\title{
Shrinking areas and mortality: an artefact of deprivation effects?
}

\author{
Daniel J Exeter, Z Feng, Robin Flowerdew, Paul J Boyle
}

J Epidemiol Community Health 2005;59:924-926. doi: 10.1136/jech.2004.032151

There is evidence that mortality rates are highest in areas that are experiencing population decline, and researchers have recommended that this should be accounted for in health resource allocation. This research finds a significant negative association between population change and mortality for small areas in Scotland, which remains when low social class is accounted for. However, this relation disappears when the area deprivation is accounted for. It is suggested that it is more important to account for deprivation than population change in health resource allocation.

$\mathrm{R}$ esearch into the association between mortality and population change has a long history, ${ }^{1}$ but more recently Davey Smith et al $^{2}$ examined the relation between population change (1971-91) and mortality (1990-92) for 292 county boroughs and urban and rural remainders of counties in Britain. Standardised mortality ratios (SMRs) for all cause mortality were highest in those boroughs experiencing the greatest population decline. Subsequent studies confirmed this negative relation for most causes of death ${ }^{3}$ and in other European countries. ${ }^{45}$ Davey Smith et al ${ }^{2}$ suggest that because "resources are allocated largely according to population size, and local and health authority budgets have therefore fallen most in these shrinking areas over time" (page 1440), resource allocation should be changed to reflect this inequity.

In the studies above, attempts were made to account for socioeconomic circumstances. For example, Davey Smith et $a l^{23}$ controlled for the proportion of the population in each county borough in social classes IV or V or with unclassified social class using partial correlations and, although this weakened the population change/mortality relation, the change was small and the broad conclusions remained unchanged.

These British studies used quite large geographical areas in their analysis, within which the range of socioeconomic variation is likely to be large, therefore masking more subtle local variations in socioeconomic circumstances. Also, while low social class is one measure that can be used to control for socioeconomic circumstances, a more common approach, in British studies especially, is to use a deprivation score. It is therefore possible that variations in population change and socioeconomic circumstances have not been controlled for adequately. In this analysis we compare the relation between population change (19812001) and mortality (1999-2001) for small geographical areas in Scotland, controlling separately for the proportion of the economically active population belonging to low social class and the deprivation circumstances of these areas.

\section{DATA AND METHODS}

Mortality data for 1999-2001 were obtained from the General Register Office for Scotland (GROS) from which we calculated indirectly SMRs. The national 2001 census population was used as the base population. The deaths were distributed among 10057 newly defined geographical areas in Scotland, designed to be consistent through time. In 2001, the total populations for these consistent areas through time (CATTs), ranged from 50 to 18510 , with an average population of 503, and a standard deviation of 831. They allow data from the 1981, 1991, and 2001 censuses to be compared reliably. ${ }^{6}$

We calculated population change between the 1981 and 2001 censuses; there is evidence that the population denominators from the 1981 and 2001 censuses are more reliable than for $1991 .^{78}$ We also required measures of low social class and deprivation for these areas. The Office for National Statistics (ONS) replaced the social class measure used in the previous British studies ${ }^{2}{ }^{3}$ with the National Statistics Socio-Economic Classification (NS-SEC) in 2000. We approximated the proportion of the economically active population belonging to social classes IV, V, or unclassified in the CATTs from the 2001 census, using the methodology recommended by the ONS. ${ }^{9}$ Carstairs deprivation scores were also calculated for CATTs based on 2001 census data.

The CATTs were then aggregated into two sets of population weighted quintiles (each quintile contained about one million people) based, firstly, on the proportion of economically active people in a low social class and, secondly, on the deprivation score. Within each quintile, the CATTs were then divided into three categories: "declining areas" experiencing at least $10 \%$ population reduction between 1981 and 2001; "growing areas" experiencing at least $10 \%$ population increase between 1981 and 2001; and "stable areas" that fell in between. SMRs were then calculated for these three categories nationally, for all 15 of the population change/low social class categories and all 15 of the population change/deprivation categories, allowing the SMRs to be compared across these groups.

\section{What this study adds}

- A negative relation exists between mortality and population change for small areas in Scotland, which remains broadly consistent when low social class is accounted for.

- However, the relation between mortality and population change disappears when deprivation circumstances are accounted for.

Abbreviations: SMR, standardised mortality ratio; CATT, consistent areas through time 


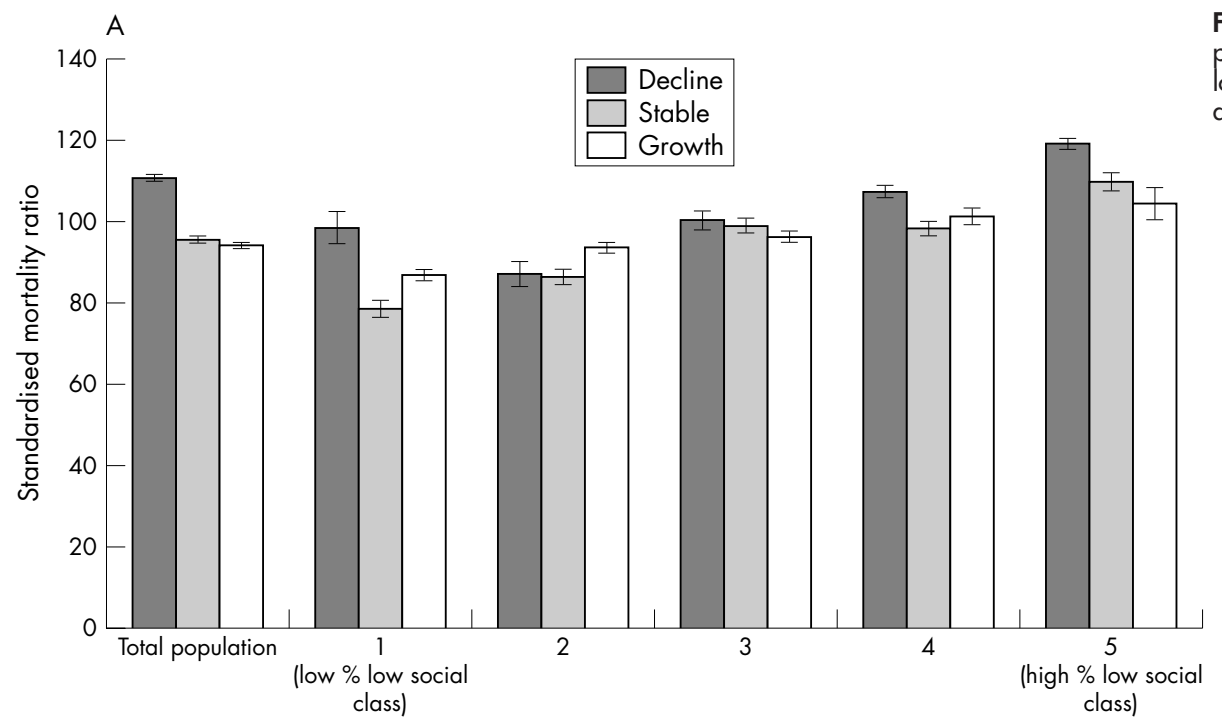

Figure 1 Mortality (1999-2001) by population change category and (A) low social class quintile, and (B) deprivation quintile.

Population weighted social class quintiles (SC IV, V, and unclassified)

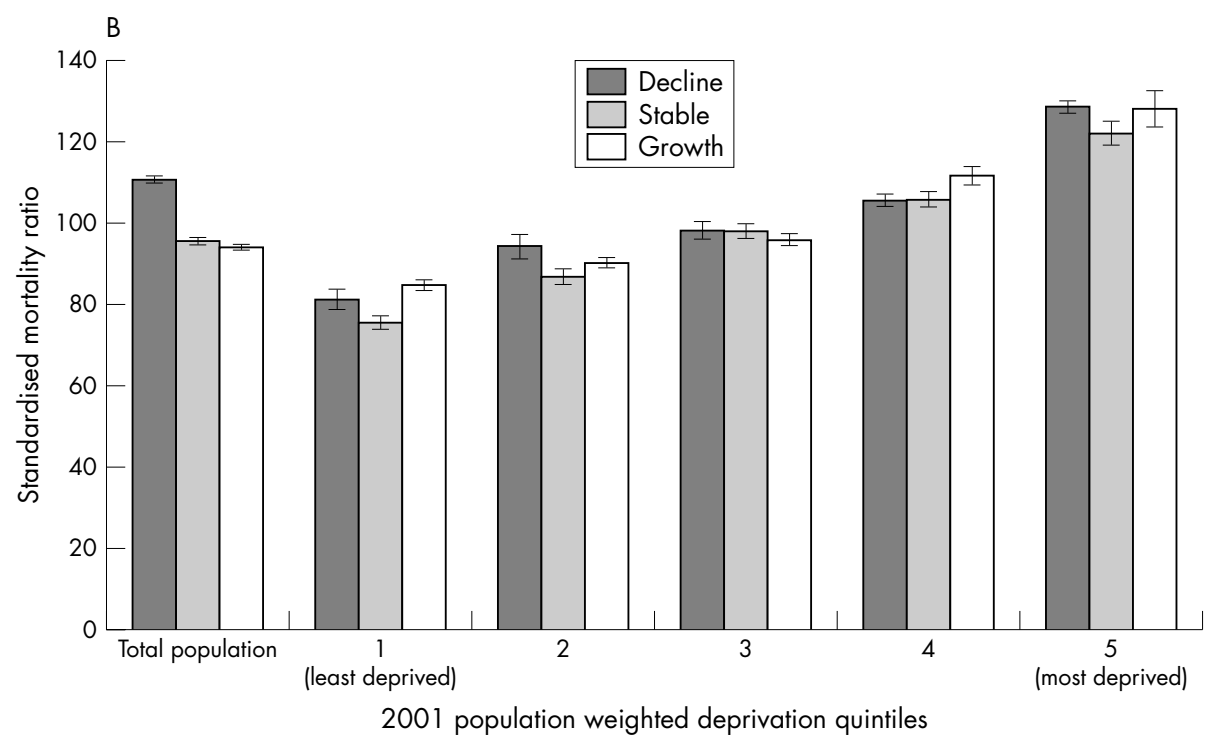

Because the SMR based analyses did not control statistically for social class or deprivation, we also modelled the relation between population change and mortality for the 10057 CATTs. Poisson regression was used to test whether the negative relation between mortality and population change remained after controlling separately for the proportion of the economically active population who were in a low social class, and deprivation. The count of all deaths in each CATT was the dependent variable and the percentage population change between 1981 and 2001, the proportion of the economically active population in low social class, and the Carstairs deprivation score were used as explanatory variables. The log of the expected deaths in each CATT was included as an offset.

\section{Policy implications}

Our results suggest that deprivation circumstances, rather than population change, should continue to be prioritised in the allocation of health resources.

\section{RESULTS AND DISCUSSION}

As expected, there was a negative relation between population change and mortality (first block of three columns, fig lA). The SMR for declining areas was significantly higher than both stable areas and growing areas, although the SMR for stable areas was not significantly different to the SMR for areas that experienced population growth.

The remaining 15 columns of figure 1A showed a mortality gradient with SMRs highest in the CATTs with a high proportion of economically active people in social class IV, V, or unclassified. Note, also, that the population change gradient remained reasonably consistent across the social class quintiles, except in quintile 2 . These results broadly confirm the earlier findings of Davey Smith et al. ${ }^{2}{ }^{3}$

However, when we compared the SMRs for the 15 population change/deprivation categories, the population change gradient disappeared. The SMRs for the declining areas were not significantly different to the SMRs for growth areas, except in quintile 4 where the SMR for declining areas was actually lower than the SMR for growth areas (fig 1B).

These relations were examined statistically using Poisson regression (table 1). Model 1 provides the log likelihood 
Table 1 Modelling results

\begin{tabular}{|c|c|c|c|c|}
\hline & Log likelihood & Parameter estimate & Standard error & p Value \\
\hline Model 1 & -36163.89 & & & \\
\hline Intercept & & 0.0002913 & 0.0023979 & 0.903 \\
\hline Model 2 & -35900.276 & & & \\
\hline Population change & & -0.0010804 & 0.0000496 & 0.000 \\
\hline Intercept & & 0.0137462 & 0.0024596 & 0.000 \\
\hline Model 3 & -35297.831 & & & \\
\hline$\%$ Low social class & & 0.0163886 & 0.0003926 & 0.000 \\
\hline Intercept & & -0.235846 & 0.0062537 & 0.000 \\
\hline Model 4 & -33740.285 & & & \\
\hline Deprivation & & 0.534964 & 0.000752 & 0.000 \\
\hline Intercept & & -0.0031818 & 0.0024103 & 0.187 \\
\hline Model 5 & -35236.966 & & & \\
\hline Population change & & -0.0005274 & 0.0000492 & 0.000 \\
\hline$\%$ Low social class & & 0.0150144 & 0.0004116 & 0.000 \\
\hline Intercept & & -0.20945 & 0.0066867 & 0.000 \\
\hline Model 6 & -33739.731 & & & \\
\hline Population change & & 0.0000488 & 0.0000492 & 0.291 \\
\hline Deprivation & & 0.0537913 & 0.0008024 & 0.000 \\
\hline Intercept & & -0.0038136 & 0.0024843 & 0.125 \\
\hline
\end{tabular}

measure of fit for the null model, which only includes a constant. The percentage population change between 1981 and 2001 was negatively and significantly associated with deaths from all causes in 1999-2001 (model 2, table 1). The proportion of the population in low social class was positively and significantly associated with mortality (model 3, table 1 ), as was the Carstairs index of deprivation (model 4, table 1). With a reduction in the log likelihood of 2243.6, the deprivation score had greater explanatory power than either population change (236.6) or low social class (866.1).

Model 5 provides the relation between population change and mortality, controlling for low social class. The population change variable remained negative and significant, while low social class also remained positively and significantly associated with mortality.

However, when we modelled population change and mortality, controlling for deprivation (model 6, table 1), the coefficient for the population change variable became insignificant. Deprivation remained significantly and positively associated with mortality.

These results suggest that the relation between population change and mortality in Scotland at this scale of analysis is an artefact of the relation between area deprivation and mortality. Areas of population decline are disproportionately drawn from areas of high deprivation. The population change gradient remains after controlling for social class, but disappears once deprivation is controlled for. We suggest that it is more important to account for deprivation than population change in health resource allocation, although it is important to acknowledge the unique health care circumstances in areas where the population is declining. Deprivation is already accounted for in health care funding in Scotland, although it is debateable whether the weighting given to this factor is adequate; recent suggested changes to the Arbuthnott formula ${ }^{10}$ showed that unmet need should also be accounted for, and this is likely to be substantially higher in more deprived areas.

\section{ACKNOWLEDGEMENTS}

Census output is Crown copyright and is reproduced with the permission of the Controller of HMSO and the Queen's Printer for Scotland.

\section{CONTRIBUTORS}

All authors participated in design, execution, analysis, and write up of different parts of the study. Paul Boyle had the main coordinating responsibility for the study design and Daniel Exeter for the analysis. All authors had access to the study data and agreed to submit for publication.

\section{Authors' affiliations}

D J Exeter, Z Feng, R Flowerdew, P J Boyle, School of Geography and Geosciences, University of St Andrews, St Andrews, UK

P J Boyle, Social Dimensions of Health Institute, Dundee and St Andrews, UK

Funding: Daniel Exeter's PhD was funded by an Overseas Research Student award, and by a University of St Andrews Lapsed Bursary award.

Conflicts of interest: none.

Correspondence to: Dr D Exeter, School of Geography and Geosciences, University of St Andrews, St Andrews KY16 9AL, UK; d.exeter@st-andrews.ac.uk

Accepted for publication 10 May 2005

\section{REFERENCES}

1 Lewis-Faning E. A survey of the mortality in Dr Farr's 63 healthy districts of England and Wales during the period 1851-1925. Journal of Hygiene 1930;30:121-53.

2 Davey Smith G, Shaw M, Dorling D. Shrinking areas and mortality. Lancet 1998;352:1439-40.

3 Davey Smith G, Shaw M, Dorling D. Population change and mortality in men and women. J Epidemiol Community Health 2001;55:9.

4 Molarius A, Janson S. Population change and mortality in men and women. J Epidemiol Community Health 2000;54:772.

5 Regidor E, Calle ME, Domínguez V, et al. Inequalities in mortality in shrinking and growing areas. J Epidemiol Community Health 2002;56:919-21.

6 Exeter D, Boyle PJ, Feng Z, et al. The creation of 'consistent areas through time' (CATTs) in Scotland, 1981-2001. Popul Trends 2005;119:28-36.

7 Boyle P, Exeter D, Flowerdew R. The role of population change in widening the mortality gap in Scotland. Area 2004;36:164-73.

8 Simpson S, Dorling D. Those missing millions - implications for social statistics of nonresponse to the 1991 census. J Soc Policy 1994;23:543-67.

9 Office of National Statistics. Continuity issues: SC, SEG, and NS-SEC http:// www.statistics.gov.uk/methods_quality/ns_sec/continuity.asp (accessed 7 Feb 2005).

10 McConnachie A, Sutton M. Derivation of an adjustment to the Arbuthnott formula for socioeconomic inequities in health care, Report to the Standing Committee on Resource Allocation. Edinburgh: Scottish Executive, 2004. 